\title{
Effect of hydrophobized starch granules on cereal foods - Importance of wheat starch granule surface protein
}

\author{
Masaharu Seguchi* \\ Kobe Women's University, Japan
}

\begin{abstract}
While investigating the flour chlorination that started to whiten the flour, hydrophobicization of wheat starch granules was found by colloidal observation, and the same hydrophobization was found even after dry heat treatment $\left(120^{\circ} \mathrm{C}, 2\right.$ hours) of wheat flour and left at room temperature for a long time. It was speculated that the cause of the high quality of castella by aging wheat flour, which had been unknown so far, was probably the hydrophobicization of wheat starch granules, and the involvement of proteins on the surface of wheat starch granules was significant.

By improving the elasticity of the hot cake structure, producing high-quality castella, and, in the case of rice/wheat flour bread, by reducing the wheat glutenin SS bond due to its hydrophobicity, the rice/wheat flour bread is dry heat treating the wheat flour or left to stand at room temperature for a long time. It was found that this affected the deterioration of the bread making properties.
\end{abstract}

\section{Ancient people wanted white powder}

Wheat has a harder skin than rice and adheres strongly to the endosperm, making it difficult to remove. For this reason, the grains are crushed to remove the hard rind and made into flour. Humans wanted white flour and advanced the milling technology to remove wheat husks, resulting in fairly white flour. However, it did not turn white any more. This is a story from ancient Egypt, Greece, and Roman times. Ancient people wanted to eat white bread and white cake. Since ancient times, how to make flour white has been a big problem. Furthermore, the bleaching effect by the drug was performed, and more specifically, the bleaching (chlorination) effect by chlorine gas. Degradation of the carotenoid pigment lutein in wheat flour. Bleaching with flour chlorination was effective. For more than 97 years, the effect of chlorine gas on soft wheat flour has been improved in the United States [1]. In addition to bleaching effects, chlorination was also found to improve cake quality. The cake volume was improved, the texture was uniform, the cake was white in color, the cake shape was uniform, and the texture was good [2-6]. Fruit holding in the cake also occurred [7]. The effects of chlorination on wheat flour are diverse, and studies have been conducted on wheat protein [8], starch [9] lipids [10,11], pentosan [12], water absorption [13], and lipophilicity [14]. The effect on all flours was shown by chlorination [15].

\section{Birth of hot cake (a kind of pancake)}

About 60 years ago, when hot cakes were born, the Japanese diet was still the same, and it was a low-calorie, low-calorie Japanese food such as rice, pickled radish, pickled plums, and dried fish. It's no wonder that mothers want to see foreign movies and want their children to eat cakes that have just been baked in the oven. But in Japan, the oven is not in the kitchen. One is a frying pan. At that time, a hot cake that was quickly baked using this frying pan and eaten while hot was invented. But this hot cake was poor in cake suitability and immediately became a dumpling in the oral cavity and lost its tissue elasticity. At that time, flour was chlorinated overseas. The introduction of this method was very effective for improving Japanese hot cakes. When baked with chlorination flour, the tissue elasticity of the pancake was retained in the oral cavity (Figure 1).

Thus, chlorination flour came to be used as flour for hot cakes. However, it was soon discontinued in Japan due to the danger of using chlorine gas in the factory and the danger of chlorine gas coming from the cake to the human body. This improved method is still widely used in the United States. We stopped chlorination, but there was no alternative. It was unclear why the chlorination of flour caused the pancake to have strong tissue elasticity. It was clear that the chlorination treatment of wheat flour caused some important chemical changes and was involved in the improvement of the texture of the hot cake, but the cause was unknown. However, hygiene of chlorination treatment of wheat flour is not good, and there is a strong demand around the world to avoid this improvement method. If we do not know what this effect is when mixing chlorine gas with flour, we cannot avoid this method and obtain a safer method. The chlorination treatment method [16] is a method in which a certain amount of wheat flour (about $14 \%$ water content) is placed in a box that rotates at room temperature and chlorine gas is blown directly into it. In a moment, the flour turns white and the chlorine odor disappears. After taking a part of the wheat flour and suspending it in water, the $\mathrm{pH}$ is measured to measure the treatment level. The tissue elasticity of hot cakes was improved at extremely low treatment levels (approximately chlorine $0.3 \mathrm{~g} / \mathrm{kg}$ flour).

\section{On the improving effect of chlorination flour}

A full-scale study of flour chlorination was carried out by Solars $[17,18]$. First, wheat flour is divided into water-soluble (WS), gluten $(\mathrm{G})$, prime starch (PS), and tailings (T) categories, and then mixed at

${ }^{*}$ Correspondence to: Masaharu Seguchi, Kobe Women's University, Japan, E-mail: seguchi@suma.kobe-wu.ac.jp

Received: June 02, 2020; Accepted: June 23, 2020; Published: June 26, 2020 


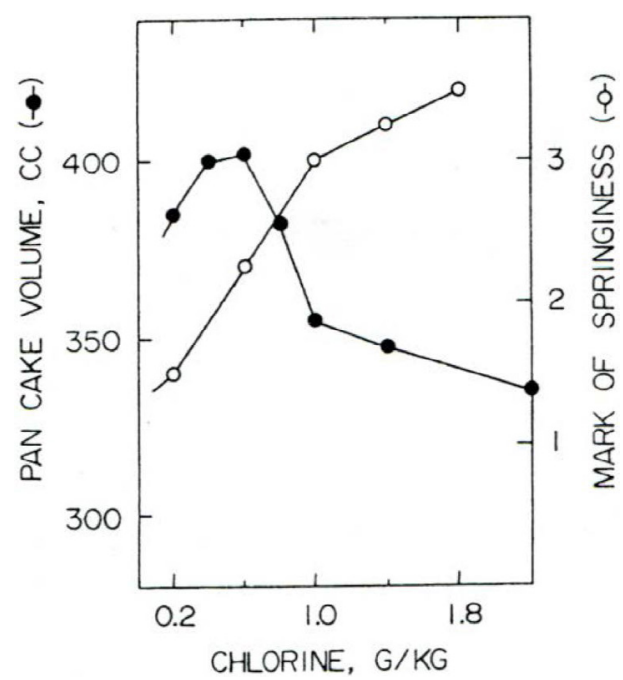

Figure 1. Effect of chlorination on hot cake (pan cake) volume and springiness

the original ratio to prepare a reconstituted flour, and cake baking is carried out accordingly. Using this method, the research on chlorination flour was promoted while the interchange between flour fractions was performed. We are investigating which category of cake flour changes due to chlorination. And it was shown that the effect of chlorination flour on the cake was due to PS classification. Later, similar results were obtained by other researchers [19-21]. We [19] use the untreated chlorinated flour and the treated flour. Fractionation of each section (WS, G, PS, T) and replacement between each section, proceeded hot cake baking experiment with reconstituted flour (eg, WS, G, T from untreated flour + PS from treated wheat), It was clarified that PS classification of chlorination flour showed the effect of improving the tissue elasticity of hot cake. It was. Fractionation of flour for hot cakes [22] was performed as follows (Figure 2). Water is added to the flour, and the mixture is stirred with a Waring blender and then centrifuged to separate water-soluble (WS) fraction (water-soluble polysaccharides, proteins, amino acids, peptides, sugars, etc.) in the flour first, and the precipitate is separated. Suspended in an acetic acid solution $(\mathrm{pH}$ $3.5)$ and dissolved in this was classified as gluten $(\mathrm{G})$. The $\mathrm{pH}$ of the insoluble matter is returned to 5.0, and the precipitate is separated into two layers by stirring and centrifuging. The yellow, sticky one in the upper layer is the tailings $(\mathrm{T})$ fraction (meaning water-insoluble proteins, polysaccharides, smaller starch granules, waste such as lipids), and the pure white section in the bottom is the prime starch (PS) fraction. It consisted of larger starch granules. Wheat starch granules consist of larger granules $(20 \mu \mathrm{m}$ on average $)$ and small granules $(2 \mu \mathrm{m}$ on average) with different biosynthetic mechanisms. In this way, the wheat flour was fractionated into 4 fractions and the recovery rate was almost $100 \%$ (WS fraction $10 \%$, G fraction $10 \%$, T fraction $40 \%$, PS fraction $40 \%$ ). A hot cake was produced with good reproducibility by baking according to the stirring time, the liquid/solid ratio, and the $\mathrm{pH}$ of the original flour. It was found that the hot cakes had tissue elasticity when only the PS fraction obtained from chlorination flour were replaced [19] (Table 1). Then, what kind of change occurred in wheat starch granule (PS fraction) in chlorination flour and what is related to the tissue elasticity of this hot cake? Whistler et al. [23-25] studied the effect of chlorination on wheat starch. They reported a unique oxidative depolymerization reaction of starch molecules by chlorination under low water content. When hot cake baking was performed with the reconstituted flour consisting of wheat flour WS fraction, G fraction, PS fraction, and $\mathrm{T}$ fraction, when only the PS fraction was replaced with the category from chlorination flour, the hot cake became elastic. When the sucrose fatty acid ester (SFAE=Sucrose Fatty Acid Ester) was placed in this batter, the result was that the tissue elasticity disappeared [19] (Table 1). Around that time, Tomie et al. [26] investigated the formation of egg gel nest formation by a method in which air bubbles were trapped by a nylon filament. Regarding the air bubble trapping behavior, high air bubble adhesion was found in the order of strong hydrophobicity: cotton=hemp $<$ acrylic=polyvinyl chloride $<$ silk $<$ wool $<$ nylon. They studied the adhesion of bubbles by paying attention to the difference in hydrophilicity and hydrophobicity of those fibers. In other words, the property of hydrophobicity stabilizes the bubbles by attaching bubbles (originally bubbles are hydrophobic on the surface) to the fiber surface. We got the hint from this experiment and proceeded the following experiments. The hole slide glass used for the microorganism experiment was used. A drop of an aqueous starch granule suspension (so that several dozen starch granules down on the hollow of a whole slide glass. The starch granules in the water droplet sinked in just a few seconds due to gravity, which was observed under a microscope. Using this method, the behavior of starch granules from chlorinated wheat

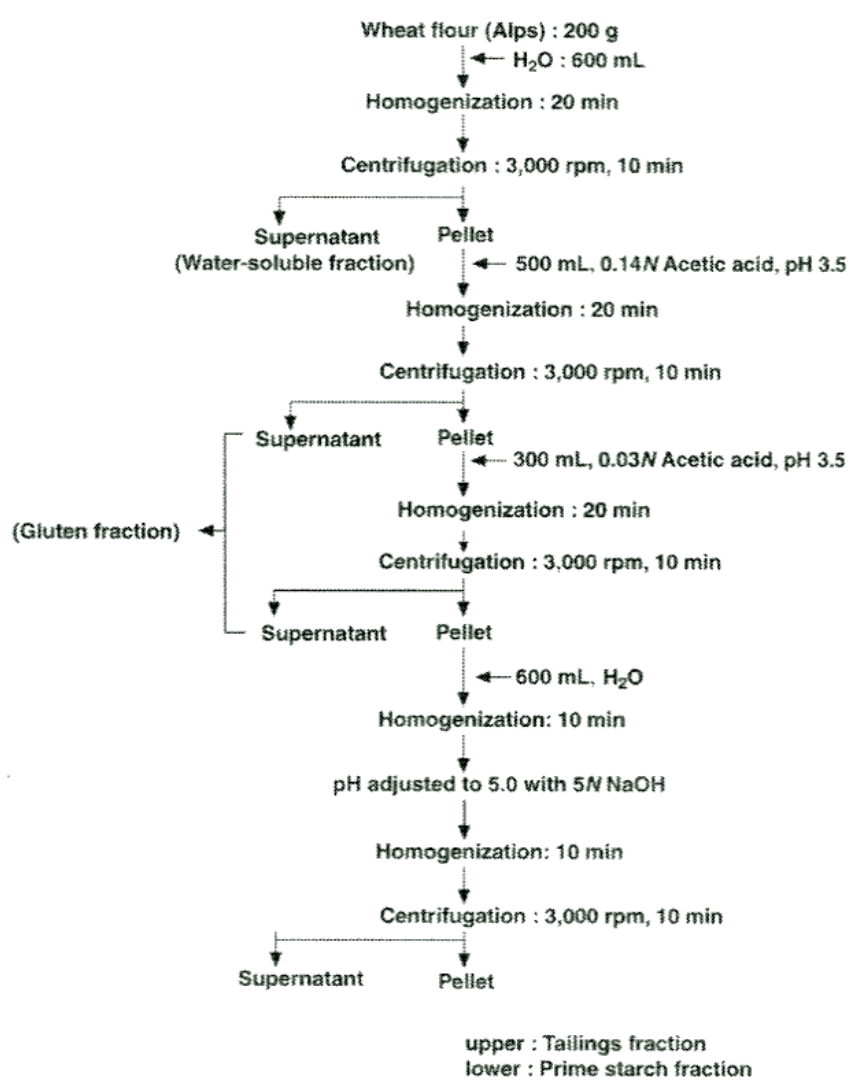

Figure 2. Acetic acid fractionation of wheat flour

Table 1. Baking results of reconstituted, unchlorinated wheat flour replacing the prime starch fraction only from chlorinated flour

\begin{tabular}{|c|c|c|c|}
\hline $\mathbf{C l}_{\mathbf{2}}$ Rate (g/kg) & Volume $\left.\mathbf{( c m}^{\mathbf{3}}\right)$ & Gumminess & Springiness \\
\hline 0.0 & 331 & 4.0 & 0.0 \\
\hline 0.4 & 345 & $3.5(3.5)^{\mathrm{b}}$ & $1.0(1.5)$ \\
\hline 0.8 & 360 & $2.0(4.0)$ & $2.5(1.0)$ \\
\hline 1.2 & 355 & $0.5(4.0)$ & $3.5(1.5)$ \\
\hline 1.6 & 355 & $0.5(4.0)$ & $3.5(1.5)$ \\
\hline 2.0 & 328 & $0.0(3.0)$ & $4.0(3.0)$ \\
\hline
\end{tabular}

${ }^{\mathrm{b}} \mathrm{A}$ number in parentheses indicates the value when sucrose fatty acid ester is added. 
flour and untreated wheat flour in water was compared. In the former, when the grains were close to each other in water, strong adsorption was observed as if there was a magnetic force at a certain position on the starch grain surface. This behavior was never seen in the latter. It was found that the starch grains of chlorination wheat flour were close to each other and adsorbed one after another at convenient positions. That is, it seems that some reactive groups were generated on the grain surface. At this time, when the sucrose fatty acid ester aqueous solution was put into this, the property of the cluster disappeared in an instant. From this, it was speculated that this property of aggregation might be due to the formation of hydrophobic groups on the starch granule surface by chlorination (Figure 3). Corresponding to the addition of sucrose fatty acid ester to the cake batter, the elasticity gain of the hot cake disappeared, and it may be directly related to the disappearance of the agglomeration property of starch granules by sucrose fatty acid ester under the microscope. It was inferred that the hydrophobization of PS fraction (starch granules) in chlorination flour was related to the tissue elasticity of hot cakes [27]. Sucrose fatty acid ester (SFAE) is an ester bond of a hydrophilic substance (sucrose) and a hydrophobic substance (fatty acid). It is speculated that chlorination caused some changes in the surface of starch granules to make them hydrophobic, which was responsible for improving the tissue elasticity of the hot cake.

\section{Hydrophobization of starch granules by chlorination}

As a result of the reconstitution experiment of wheat flour, it was inferred that the acquisition of tissue elasticity of hot cakes by chlorination wheat flour was a change in the PS fraction, which contained approximately $40 \%$ in weak wheat flour. Hydrophobization of the starch granules in the PS section was caused by chlorination, and it was necessary to quantify this hydrophobicity, so its lipophilicity was investigated. This is an experiment in which starch granules from chlorinated wheat flour and starch granules from non-chlorinated wheat flour are placed in a test tube and stirred vigorously with oil (any liquid may be used) in water. The chlorinated one showed a strong lipophilicity.

In water, oil is lighter than water and floats above the water layer, but when the starch granules adhere to the oil, the oil sinks in the water due to the weight of the starch granules (Figure 4). When the chlorination level was increased, the amount of precipitation increased accordingly, and the amount of hydrophobization could be quantified [28-30] (Figure 5). Under the microscope, it was observed that the starch granules from this chlorination flour were adsorbed to the oil [28], but the starch granules were tightly clogged on the surface of the oil droplets in the form of dumplings. Furthermore, it was observed that the starch granules were tightly packed in it (Figure 6).

No such properties are observed in untreated starch granules. It was found that lipophilization by chlorination occurs not only from chlorinated wheat flour, but also by chlorination directly on the surface of wheat starch granules, and starch granules other than wheat starch granules include potato, barley, rice, corn, and litter starch. It was found that any starch granules such as granules became lipophilic by chlorination treatment to each powder [31]. Furthermore, when starch granules were subjected to various solvents and enzyme treatments, and a lipophilicity disappearance test was conducted, it was found that the starch granules disappeared by treatment with protease such as pepsin, and a chlorination reaction occurred on the protein on the starch granule surface. It was speculated that this caused hydrophobicity [28] (Table 2). The same was observed with various kind of starch granules [31]. Direct chlorination into powders of 20 amino acids and
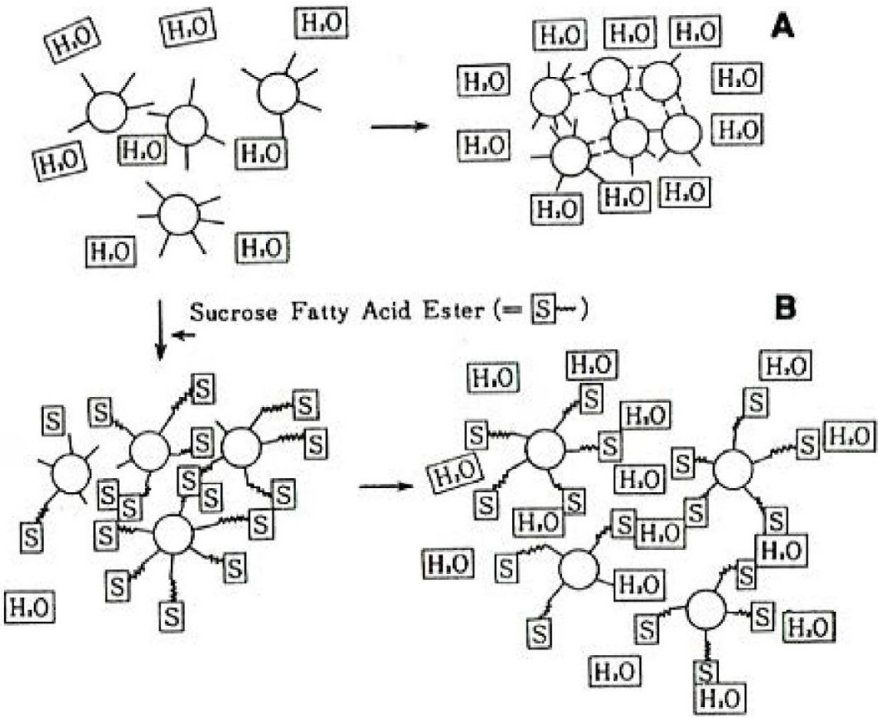

Figure 3. Cluster formation of chlorinated starch granules in water (A) and change after addition of sucrose fatty acid ester (B)

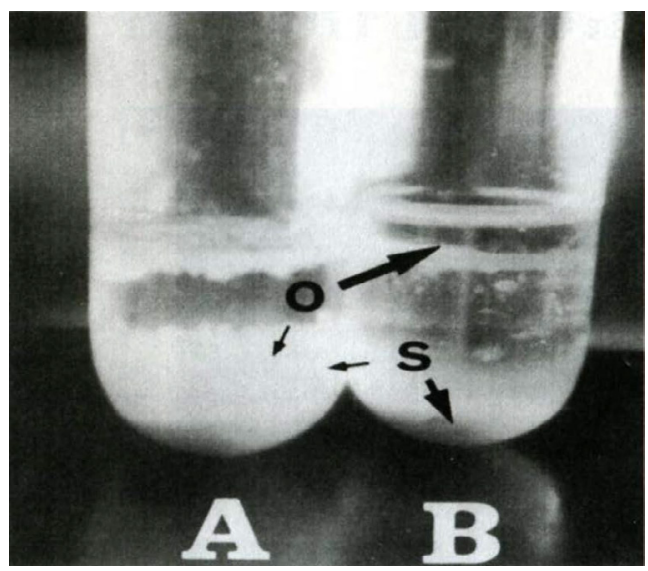

Figure 4. Mixtures of (A) Chlorinated starch $\left(2.0 \mathrm{~g}\right.$ of $\mathrm{Cl}_{2}$ gas $/ \mathrm{kg}$ of wheat flour) or (B) Nonchlorinated starch with oil in water. O-oil, $\mathrm{S}=$ starch

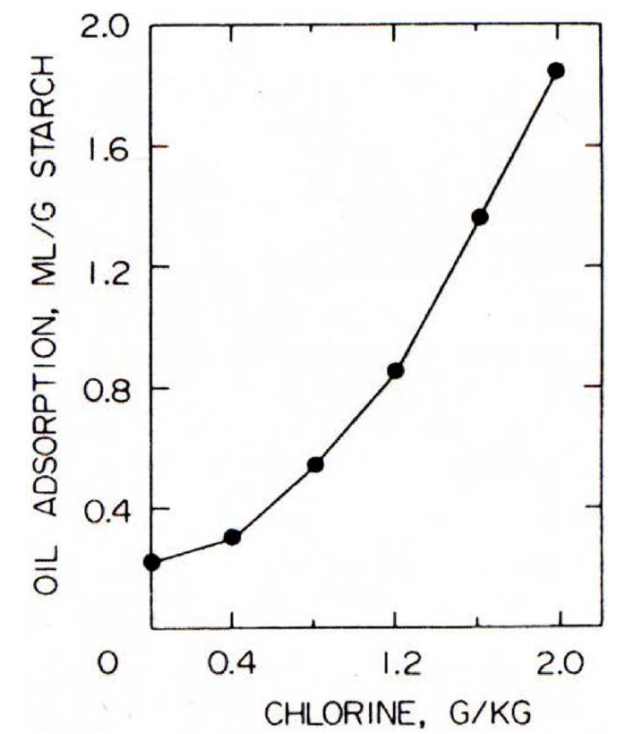

Figure 5. Effect of chlorination on oil adsorption of wheat starch 


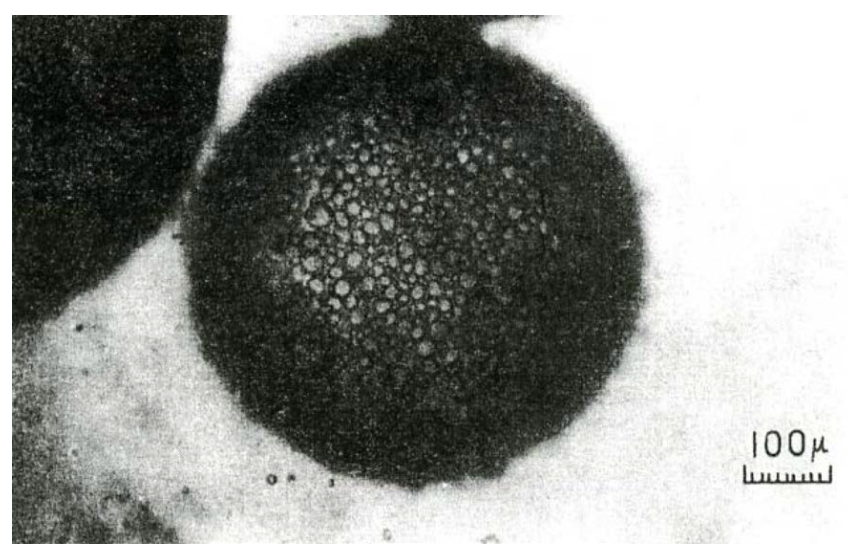

Figure 6. Photomicrograph of chlorinated prime starch granules adhering to an oil droplet

Table 2. Oil-binding capacity of chlorinated prime starch following treatment with various enzymes and certain solvents

\begin{tabular}{|l|c|c|}
\hline & \multicolumn{2}{|c|}{ Oil-binding capacity } \\
\hline Treatment & Percent & $\begin{array}{c}\text { Milliliters } \\
\text { per gram }\end{array}$ \\
\hline None & 100 & 1.4 \\
\hline Pepsin & \multicolumn{2}{|c|}{} \\
\hline $50 \mathrm{mg}$ & 0 & 0.0 \\
\hline $5 \mathrm{mg}$ & 20 & 0.1 \\
\hline $0.5 \mathrm{mg}$ & 79 & 0.3 \\
\hline Heat-denatured pepsin, ${ }^{\mathrm{c}}$ 50 mg & 0 & 1.1 \\
\hline Trypsin, 50 mg & 29 & 0.0 \\
\hline$\alpha$-Chymotrypsin, $50 \mathrm{mg}$ & 20 & 0.4 \\
\hline$\alpha$-Amylase, $5 \mathrm{mg}$ & 20 & 0.3 \\
\hline$\beta$-Amylase, 8.25 mg & 150 & 0.3 \\
\hline Chloroform-methanol & 100 & 2.1 \\
\hline Water-saturated l-butanol & 130 & 1.4 \\
\hline Sodium dodecylsulfate & 0 & 1.8 \\
\hline $7 \%$ HCl at room temperature & & 0.0 \\
\hline
\end{tabular}

observation by paper chromatography revealed spots with different $\mathrm{Rf}$ in amino acids such as tyrosine and lysine (Figure 7). It was inferred that the chlorine atom entered amino acids such as tyrosine and lysine, and the $\mathrm{Rf}$ value resulted in hydrophobicity. The position where the chlorine atom enters was also inferred from the chlorination of commercially available monoiodotyrosine and diiodotyrosine. It was also confirmed that proteins such as BSA (bovine serum albumin), which are extremely soluble in water, are dried and then chlorinated to make them insoluble even when water is added again [32]. There is a lot of debate about whether there is protein on the surface of wheat starch granules. Wheat starch granules were stained with protein dyes such as Coomassie brilliant blue, eosin Y, amido black 10B. No stain is observed under the microscope on the surface of the starch granules that are lightly stained with each dye. The fluorescent dye Fluorescamine [33] was reacted with the surface of wheat starch granules. If protein is present, it reacts with Fluorescamine and fluoresces. As a result, they all fluoresced neatly and glowed green (Figure 8). Unstained ones did not fluoresce [34]. The starch granule surface proteins in PS fraction from chlorinated wheat flour were extracted and compared with those from unchlorinated wheat flour, and an increase in the amount of protein attached was observed [35]. Just as the lipophilicity of PS fraction in chlorinationtreated wheat flour disappeared by protease treatment, lipophilicity also disappeared in the dry heat-treated wheat flour and the PS fraction in wheat flour treated at room temperature for a long time as described below. The PS fraction in the wheat flour that had been left to stand at room temperature for a long time was also considered to have been hydrophobized due to changes in starch granule surface proteins [36]. The protein on the surface of wheat starch granules was quantified by the dye binding method. The protein contained in starch granules was stained with amido black 10B [37], solubilized in a weak alkaline solution, and the amount of amido black 10B was measured by OD630 to measure the amount of bound protein $[38,39]$. Furthermore, wheat starch granules were stained with starch dye, Remazol brilliant blue, and the higher-order structure inside the granules was observed by SEM (scanning electron microscope) [40]. The internal structure of wheat starch grains could be observed without gelatinization (Figure 9). At that time, a British research group was studying the hardness of wheat grains. The hardness of wheat grains on wheat milling was an important issue. They were investigating the relationship between starch granule surface proteins and wheat grain firmness [41-49]. As a

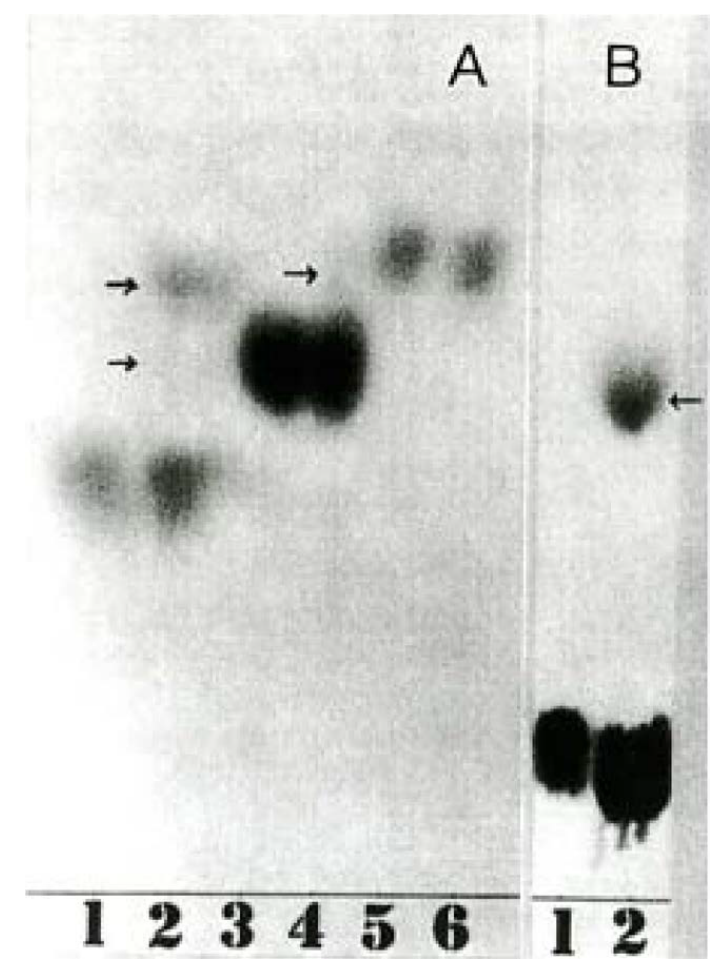

Figure 7. Paper chromatograms of A, tyrosine (1) and chlorinated tyrosine (2), monoiodotyrosine (3) and chlorinated monoiodotyrosine (4), diiodotyrosine (5) and chlorinated diiodotyrosine (6); B, lysine (1) and chlorinated lysine (2)

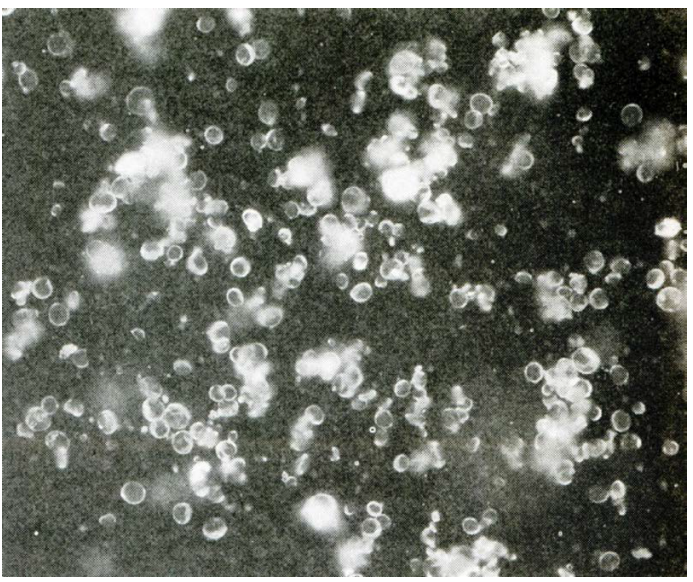

Figure 8. Fluorescence microphotograph of fluorescamine-treated wheat prime starch 
result, it led to the discovery of friabilin. The presence of protein on the surface of wheat starch granules became less questionable.

\section{Dry heat treatment of wheat flour}

The method of obtaining cake aptitude by chlorination is not a hygienic method. I searched for a safer method than chlorination. Until now, a dry heat treatment method has been reported as a flour flour cake replacement method to replace chlorination [50-55]. If dry-heattreated wheat flour has the same improvement effect as chlorination wheat flour, it should have the effect of improving the tissue elasticity of hot cake by dry-heat treatment and hydrophobizing the PS fraction in the flour. Dry heat treatment of wheat flour was performed in an open oven at $120^{\circ} \mathrm{C}$ for $0,1,2,3,5$ hours, or $110-140^{\circ} \mathrm{C}$ for 2 hours. The tissue elasticity of the hot cake was examined from the recovery of the cake bulge after pressurization (Table 3). After all, the improvement effect was recognized in the hot cake [56].

Furthermore, the dry heat treatment of wheat flour is $120^{\circ} \mathrm{C}$ for up to 8 hours, $110^{\circ} \mathrm{C}$ for up to 8 hours, $100^{\circ} \mathrm{C}$ for up to 8 hours, $90^{\circ} \mathrm{C}$ for up to 144 hours ( 6 days), and $80^{\circ} \mathrm{C}$ for up to 144 hours. The dry heat treatment wheat flour samples were prepared by changing the treatment conditions up to 240 hours at $70^{\circ} \mathrm{C}$ ( 10 days) and up to 540 hours at $60^{\circ} \mathrm{C}$ (22.5 days) (54 samples in total). The tissue elasticity and hydrophobization of hot cakes were investigated. It was confirmed that similar tissue elasticity was obtained in a short time at high temperature and in a long time at low temperature, and that hydrophobicity was obtained [57]. In the acetic acid fractionation method of wheat flour, the stirring method was changed from the conventional method using a Waring blender to the stirring method using an automatic mortar. It was possible to obtain PS fractions from wheat flour with weaker stirring than with Waring blender. In the dry heat treatment and the fractionation of wheat flour that had been left to stand at room temperature for a long time, non-separation from the $\mathrm{T}$ fraction due to the hydrophobization of the PS fraction in the four fractions (WS, G, PS, T fractions) was
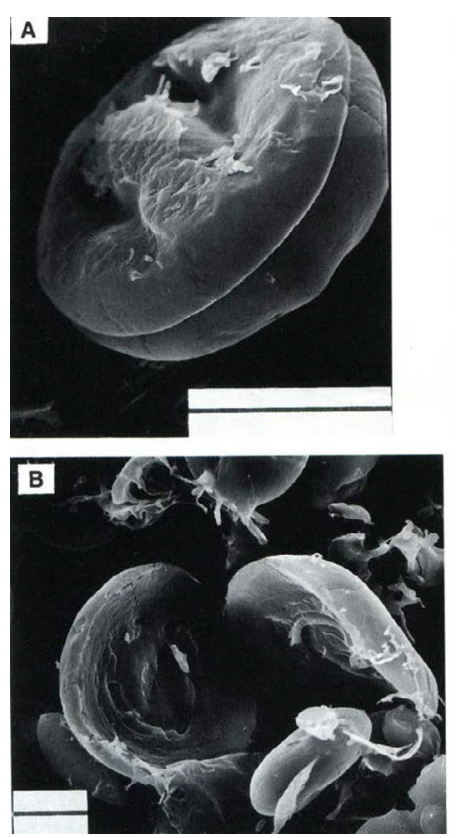

Figure 9. Scanning electron microscopy observations of wheat starch stained with Remazolbrilliant blue (RBB)dye and extracted five times with sodium dodecyl sulfate and 2-mercaptoethanol (SDS-ME) solution. A, Extracted starch with slightly hollowed equatorial groove; B, split bivalve halves of starch; C, interior of starch; and D, slippage plane of two halves of granule. $\mathrm{Bar}=10 \mu \mathrm{m}$.
Table 3. Effect of time of heating

\begin{tabular}{|c|c|c|c|c|}
\hline \multirow{2}{*}{ Conditions } & \multicolumn{2}{|c|}{ Specific volume $^{\mathrm{b}}(\mathrm{ml} / \mathrm{g})$} & \multirow{2}{*}{$\begin{array}{l}\text { Thickness after } \\
\text { releasing }(\mathrm{mm})\end{array}$} & \multirow{2}{*}{$\begin{array}{c}\text { Springiness } \\
(\%)\end{array}$} \\
\hline & Original & After pressing & & \\
\hline $0 \mathrm{hr}(9.9)^{\mathrm{e}}$ & 2.03 & 1.55 & 37.8 & 76.2 \\
\hline $0.5(6.3$ & 1.97 & 1.57 & 40.8 & 79.9 \\
\hline 1.03 .6 & 1.96 & 1.61 & 41.3 & 82.4 \\
\hline 2.00 .0 & 1.95 & 1.69 & 48.5 & 86.7 \\
\hline 3.00 .0 & 1.91 & 1.71 & 50.5 & 89.6 \\
\hline 4.00 .0 & 1.89 & 1.83 & 56.0 & 96.9 \\
\hline 5.00 .0 & 1.73 & 1.68 & 57.0 & 97.4 \\
\hline
\end{tabular}

${ }^{\mathrm{a}} \mathrm{At} 120^{\circ} \mathrm{C}$.

${ }^{\mathrm{b}} \mathrm{SD} \pm 0.014$

${ }^{\mathrm{c}} \mathrm{SD} \pm 0.5$.

${ }^{\mathrm{d}} \mathrm{SD} \pm 1.1$.

ePercentage of moisture of heat-treated flour.

Experiments were replicated twice.

confirmed by this method. There was a significant correlation between the decrease in PS classification recovery and the tissue elasticity of hot cake [58]. We collected PS fraction from dry heat-treated wheat flour and observed lipophilicity. As a result, as with chlorinated wheat flour, the starch granule surface in PS fractionobtained from dry heat treated flour also showed strong lipophilicity [59-63]. Lipophilicity was also found in chlorination and dry heat treatment experiments using microbial polysaccharide curdlan particles [64]. The dry heattreated wheat flour were fractionated with acetic acid, synthetic flours were prepared using them, and hot cake baking test was carried out by a replacement experiment. As a result, it was confirmed that tissue elasticity was obtained by dry heat treatment in PS and T fractions, and the same effect as chlorination was confirmed [65]. Thus, it was found that the starch granule surface in PS fraction was made hydrophobic by controlling the treatment time and temperature of wheat flour, and the properties were greatly changed. The interaction between the PS and T fractions, which account for 70 to $80 \%$ of the dry heat-treated wheat flour, contributed to the formation of a firm structure in the hot cake structure, so it could not be collapsed even with a slight pressurization. After that, it was confirmed that the $\mathrm{T}$ fraction was also lipophilic [66]. Why don't you lower the temperature further and extend the time? This idea uses the temperature coefficient (the reaction rate becomes $1 / 2$ to $1 / 3$ times as the reaction time decreases by $10^{\circ} \mathrm{C}$ ). If it is lowered to $120^{\circ} \mathrm{C} \rightarrow 110 \rightarrow 100^{\circ} \mathrm{C} \rightarrow \rightarrow \rightarrow$ room temperature, it should become hydrophobic even at room temperature by extending the time. From the previous experiments, it was found that the PS fraction of wheat flour was hydrophobized even at room temperature when left for a long time. Wheat flour left at room temperature $\left(15\right.$ to $20^{\circ} \mathrm{C}, 12$ months) was subjected to acetic acid fractionation one after another to collect WS, G, PS and T fractions, which extended the standing time and increased the elasticity of the hot cake. As it gradually became stronger, the interaction between the PS and T fractions due to hydrophobicity became stronger and it became difficult to separate them. There was a strong correlation between the magnitude of the interaction between the PS and T fractions and the tissue elasticity of the hot cake [67]. At first glance, it looks like nochange flour also changes from hydrophilic to hydrophobic in it. Proteins in wheat flour played an important role in the interaction between PS and T fractions [36]. Hydrophobization of the surface of chlorinated wheat starch granules is the hydrophobicization of starch granule surface proteins. Chlorine was introduced into amino acids such as tyrosine and lysine to show hydrophobicity. The same hydrophobization was shown in dry heat treatment, but chlorine was not involved in the hydrophobization. Hydrophilic groups of protein macromolecules that had been exposed to the surface by dry heat treatment were buried inside, and hydrophobic groups that had been 
buried so far were exposed to the surface, which occurred on the surface of starch granules, and the PS fraction was hydrophobized [68-72].

\section{Contribution to foam stability}

It was shown that PS fraction in chlorination, dry heat treatment, or wheat flour that had been left to stand at room temperature for a long time was hydrophobized. How the hydrophobization relates to the bubbles in the cake batter and the hot cake texture elasticity, it was unclear if it led to the improvement. Bubbles are formed in the cake batter by decomposition of sodium bicarbonate and mechanical stirring, but the bubble film is formed by protein denaturation and the bubble film is hydrophobic. If the PS fraction in the treated flour becomes hydrophobic, the starch granules will become adsorbed on the surface of the bubbles. The ore flotation method is a similar use example. Even here, bubbles are generated by stirring, but if there is nothing that stabilizes, the bubbles will disappear immediately. Amyl alcohol is used in the flotation process as a foaming agent. Metals are often hydrophobic. It is known that the powder of galena or chalcopyrite adheres to the surface of the foam and the foam has a long life. Utilizing this, each ore powder is beneficiated. An experiment was conducted to confirm whether air bubbles were stabilized when the surface of wheat starch granules was hydrophobized. A confirmation experiment was conducted to confirm whether or not the bubbles were stabilized. Water, $500 \mathrm{mg}$ of chlorinated wheat starch granules, and $2 \%$ isoamyl alcohol were placed in a test tube and stirred vigorously with a vertical shaker for 30 minutes. Isoamyl alcohol was used as the foaming agent. When the stirring was stopped, the bubbles disappeared in only a few tens of seconds, but this was photographed every few seconds. From the photograph, it was found that the starch granules of chlorination wheat flour tended to stabilize air bubbles [30]. Dry-heat-treated wheat starch granules $\left(120^{\circ} \mathrm{C}, 1,2,5\right.$ hours $) 500 \mathrm{mg}$ were similarly tested. The foam stability was compared between starch granules from wheat flour that had not been dry heat treated at all and starch granules of wheat flour that had been dry heat treated at $120^{\circ} \mathrm{C}$ for $1,2,5$ hours. Starch granules of dry-heat treated wheat flour stabilized the foam [73]. Even in the hot cake structure, the bubbles in the cake batter are stabilized by hydrophobizing the starch granules of the processed wheat flour, which contributes to the tissue elasticity of the hot cake. I thought it was done.

\section{Hydrophobized castella on castella processing}

Castella is produced by sufficiently forming egg foam, adding flour to it, and roasting it in an oven at $220^{\circ} \mathrm{C}$. If you put enough egg bubbles into the oven and then put them in a $220^{\circ} \mathrm{C}$ oven, the bubbles will disappear immediately after heating and become rubbery. If flour is added before heating, a castella structure will form. Flour is hydrophobic in nature and stabilizes the foam of eggs. Since ancient times, wheat flour for castella has been aged (room temperature for a long time) at room temperature immediately after milling. The cause was unknown, but it was known that good castella could not be made without aging. Nakamura et al. reported that the aging of wheat flour, which had been unknown for a long time in the production of castella, was due to the hydrophobicity of the PS fraction. After standing at room temperature ( 15 to $25^{\circ} \mathrm{C}, 2,4,6,8,10,12$ months), baking was performed on the castella and the increase in the specific volume of the castella was observed. At the same time, they were looking at the correlation with the increase in interaction between $\mathrm{T}$ fraction due to the hydrophobicization of PS fraction. Hydrophobization occurred in the PS fraction of wheat flour that had been left at room temperature for a long time, stabilizing the castella batter [74] (Figure 10). The specific volume of castella also increased when hydrophobization was applied to the PS fraction of wheat flour by short-time dry heat treatment $\left(120^{\circ} \mathrm{C}\right.$,
$10,20,30,60,120$ minutes) instead of leaving it at room temperature for a long time. In all cases, the stabilization of the PS fraction of each treated wheat flour into the air bubbles of eggs was stabilized by the hydrophobicity [75].

\section{Determination of hydrophobicity on the surface of wheat starch granules}

The hydrophobicity of wheat starch granules has been qualitatively and quantitatively determined by its binding property to oil, but SFAE (sucrose fatty acid ester) was used for more accurate determination. After water-soluble (HLB=about 13) SFAE was bound to the surface of the hydrophobic starch granules, excess SFAE was removed by washing with water, and then SFAE was removed from the starch granules with ethyl ether using a Soxhlet. Sucrose in SFAE was quantified by the phenol-sulfuric acid method. Hydrophobicity can be quantified using SFAE with high correlation with the results of lipophilicity so far [76] (Table 4).

\section{Rice/wheat flour bread improvement using SFAE}

Rice/wheat flour bread is made using rice flour (85\%) and wheat gluten (15\%). It was known that the baking quality (bread height, specific volume) deteriorates as rice flour ages. Rice flour was subjected to room temperature $\left(15^{\circ} \mathrm{C}, 9\right.$ months, $35^{\circ} \mathrm{C}, 14$ days $)$ or dry heat treatment $\left(120^{\circ} \mathrm{C}, 2\right.$ hours) to increase the lipophilicity of rice flour [77] and bread-making property. We confirmed the correlation of the decrease. The deterioration of bread-making property was due to the change of starch granule surface protein in rice flour. When the protein was removed with a weak alkaline aqueous solution, old rice flour lost lipophilicity and the bread-making property was restored [78] (Figure 11). It was revealed by the method of Morton [79] that the

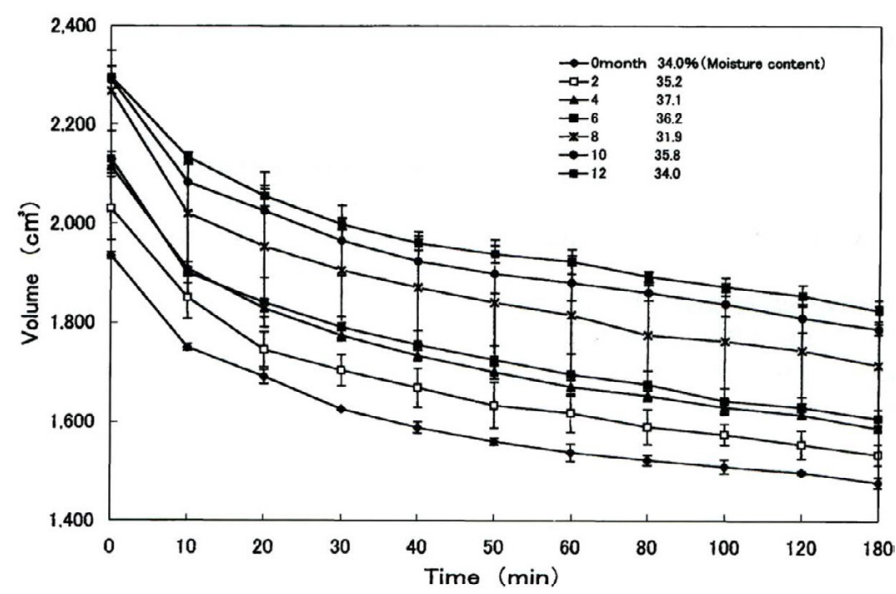

Figure 10. Effects of storage of wheat flour on the volume $\left(\mathrm{cm}^{3}\right)$ and moisture content of Kasutera cake, and changes of Kasutera cake after $180 \mathrm{~min}$ at room temperature

Table 4. Adsorption of SFAE and oil-binding to dry-heated $\left(120^{\circ} \mathrm{C}\right)$ wheat starch granules

\begin{tabular}{|c|c|c|}
\hline $\begin{array}{c}\text { Heated time } \\
(\mathbf{m i n})\end{array}$ & $\begin{array}{c}\text { SFAE (sucrose } \boldsymbol{\mu g} \text { in } \\
\text { SFAE/g starch) }\end{array}$ & $\begin{array}{c}\text { Oil-blinding } \\
\text { capacity }(\mathbf{o i l ~} \mathbf{~ m L} / \mathbf{g})\end{array}$ \\
\hline 0 & $159 \mathrm{a}(40.5)$ & $0.31 \mathrm{a}(0.12)$ \\
\hline 10 & $359 \mathrm{~b}(14.3)$ & $0.93 \mathrm{~b}(0.03)$ \\
\hline 20 & $508 \mathrm{c}(49.1)$ & $1.53 \mathrm{c}(0.15)$ \\
\hline 40 & $545 \mathrm{c}(26.8)$ & $1.79 \mathrm{~d}(0.07)$ \\
\hline 60 & $661 \mathrm{~d}(46.8)$ & $1.90 \mathrm{~d}(0.03)$ \\
\hline 120 & $712 \mathrm{~d}(20.5)$ & $1.96 \mathrm{~d}(0.01)$ \\
\hline
\end{tabular}

Notes: Values represent means of three replicates with the standard deviation in parenthesis. Means followed by different letters in columns are significantly different at $p<0.05$ according to Bonferroni's multiple range test. 


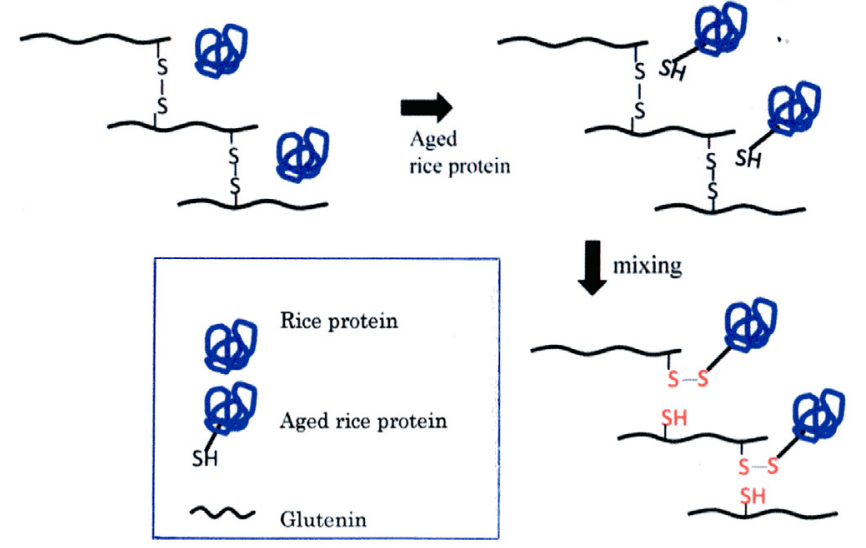

Figure 11. Wheat glutenin is reduced by SH in aged rice protein and loses its tensile strength

hydrophobicity of old rice flour on the surface of starch granules was due to the surface exposure of $\mathrm{SH}$ groups of rice starch granule surface proteins. It was speculated that the $\mathrm{SH}$ groups of the exposed rice protein reduced the SS bond of mixed wheat gluten, of which glutenin, and reduced its tensile strength to reduce the bread-making property of rice flour bread [78]. When SFAE was added to the surface of aged rice starch granules, the hydrophobic groups disappeared and the baking quality was restored [80].

\section{Conclusions}

While investigating the wheat chlorination that started to whiten the wheat flour, we found that the wheat starch granules were hydrophobized from colloidal observations. Furthermore, the same effect was obtained when the wheat flour was dry heat treated $\left(120^{\circ} \mathrm{C}\right.$, 2 hours) and left for a long time at room temperature. It was speculated that the cause of the high quality of

castella by aging wheat flour, which had been unknown so far, was probably the hydrophobicization of wheat starch granules, and the involvement of proteins on the surface of wheat starch granules was significant. One had forgotten to use the precious wheat flour and left it at room temperature for a long time and would like to throw it away, but there is an old story that when he baked a biscuit on a sick child, he made a wonderful one. This may also be the hydrophobization of flour. Furthermore, the study of rice/wheat flours bread revealed that even the old rice flour had hydrophobicity on the starch granule surface proteins. Stability of tissue (improvement of elasticity of hot cake texture), stability of foam (production of high quality castella), hydrophobicity of rice due to hydrophobicity caused by dry heat treatment of wheat flour or left at room temperature for a long time. It was found that the reduction of the wheat glutenin SS bond caused by the influence of glutenin on the bread making property of rice flour bread. This paper is a call for more attention to the processing of foods such that grains should be left at room temperature for a long time, and that hydrophobic treatment by dry heat treatment should be given more attention.

\section{References}

1. Bailey CH, Johnson AH (1923) Studies of wheat flour grades III. Effect of chlorine bleaching upon the electrolytic resistance and hydrogen-ion concentration of water extracts. J Assoc Off Agric Chem 6: 63.

2. Sollars WF (1958) Cake and cookie flour fractions affected by chlorine bleaching. Cereal Chem 35: 100-110.

3. Kissell LT (1959) A lean-formula cake method for varietal evaluation and research. Cereal Chem 36: 168-175.
4. Wilson JT, Donelson DH (1965) Studies on the dynamics of cake-baking II. The interaction of chlorine and lipid in the formation of layer-cake structure. Cereal Chem 42: $25-37$.

5. Miller BS, Trimbo HB (1965) Gelatinization of starch and white layer cake quality Food Technol 19: 208.

6. Gaines BCS, Donelson JR (1982) Contribution of chlorinated flour fractions to cake crumb stickiness. Cereal Chem 59: 378-380.

7. Cornford SJ (1961) The mechanism of fruit holding in high-ratio cake batters. $J$ Sci Food Agric 12: 693-700.

8. Tsen CC, Kulp K, Daly CJ (1971) Effects of chlorine on flour proteins, dough properties and cake quality. Cereal Chem 48: 247-254.

9. Kulp K, Tsen CC, Daly CJ (1972) Effect of chlorine on the starch component of soft wheat flour. Cereal Chem 49: 194-200.

10. Youngquist RW, Hughes DH, Smith JP (1969) Effect of chlorine on starch-lipid interaction. (Abstr.) AACC-54th Annual Meeting, Chicago, Illinois.

11. Kissell LT, Donelson JR, Clements RL (1979) Functionality in white layer cake of lipids from untreated and chlorinated patent flours. I. Effects of free lipids. Cereal Chem 56: 11-14.

12. Kulp K (1972) Some effects of chlorine treatment of soft wheat flour. Baker's Dig 46 26-32.

13. Huang G, Finn JW, Varriano-Marston E (1982) Flour chlorination. I. Chlorine location and quantitation in air-classified fractions and physicochemical effects on starch. Cereal Chem 59: 496-500.

14. Shuey WC, Rask OH, Ramastad PE (1963) Measuring the oil-binding characteristics of flour. Cereal Chem 40: 71-77.

15. Varriano-marston E (1985) Flour chlorination: new thoughts on an old topic. Cereal Foods World 30: 339-343.

16. Wallace \& Tiernam (1954) Instruction Book Number SK-1643 for instllation, operation and maintenance of Wallace \& Tiernan apparatus. Wallace \& Tiernan Inc., 25 Main Street, Belleville, N.J.

17. Sollars WF (1958) Fractionation and reconstitution procedures for cake flours. Cereal Chem 35: 85-99.

18. Sollars WF, Rubenthaler GL (1971) Performance of wheat and other starches in reconstituted flours. Cereal Chem 48: 397-410.

19. Seguchi M, Matsuki J (1977) Studies on pancake baking. Effect of chlorination of flour on pan-cake qualities. Cereal Chem 54: 287-299.

20. Johnson AC, Hoseney RC (1979) Clorine treatment of cake flours. III. Fractionation and reconstitution techniques for $\mathrm{Cl}_{2}$-treated and untreated flours. Cereal Chem 56 : 443-445.

21. Gaines CS (1982) Technique for objectively measuring a relationship between flour chlorination and cake crumb stickiness. Cereal Chem 59: 149-150.

22. Seguchi M, Matsuki J (1977) Studies on pancake baking. III. Effects of pH, mixing time, and moisture level on the quality of pancake from reconstituted flour. Cereal Chem 54: 1056-1061.

23. Whistler RL, Mittag TW, Ingle TR (1966) Mechanism of starch depolymerization with chlorine. Cereal Chem 43: 362-371.

24. Uchino N, Whistler RL (1962) Oxidation of wheat starch with chlorine. Cereal Chem 39: 477-482.

25. Ingle TR, Whistler RL (1964) Action of chlorine on semidry starch. Cereal Chem 41 474-483.

26. Tomie H, Okubo K (1984) Sudachi (porous gel) in cooking. Part 2. The correlation of formation between from bubble from air dissolved solution and "Su" during gelation of eggs. J Home Economics of Japan 35: 760-764.

27. Seguchi M (1993) Contribution of wheat starch granule hydrophobicity to pancake texture. Cereal Foods World 38: 493-497.

28. Seguchi M (1984) Oil-binding capacity of prime starch from chlorinated wheat flour Cereal Chem 61: 241-244.

29. Seguchi M (1985) Oil-binding ability of gelatinized prime starch granules from chlorinated wheat flour. Starch 37: 116-118.

30. Seguchi M (1987) Effect of chlorination on the hydrophobicity of wheat starch. Cereal Chem 64: 281-282. 
31. Seguchi M (1984) Oil-binding capacity of prime starch from chlorinated wheat flour. Cereal Chem 61: 241-244.

32. Seguchi M (1985) Model experiments on hydrophobicity of chlorinated starch and hydrophobicity of chlorinated surface protein. Cereal Chem 62: 166-169.

33. Weigele M, Debernardo SL, Tengi JP, Leimgruber W (1972) Novel reagent for the fluorometric assay of primary amines. J Am Chem Soc 94: 5927-5928.

34. Seguchi M (1986) Dye binding to the surface of wheat starch granules. Cereal Chem 63: $518-520$.

35. Seguchi M (1990) Study of wheat starch granule surface proteins from chlorinated wheat flours. Cereal Chem 67: 258-260.

36. Kusunose C, Noguchi S, Yamagishi T, Seguchi M (2002) Binding of prime starch to tailings fraction by proteins in stored wheat flour. Food Hydrocoll 16: 73-77.

37. Nakao T, Nakao M, Nagai F (1973) Microdetermination of protein not affected by the presence of various buffers, sucrose, ATP, and eluates from polysaccharide derivatives. Anal Biochem 55: 358-367. [Crossref]

38. Seguchi M, Yoshino Y (1999) Microdetermination of surface proteins of wheat starch granules by dye binding. Cereal Chem 76: 410-412.

39. Yoshino Y, Hayashi M, Seguchi M (2005) Presence and amounts of starch granule surface proteins in various starches. Cereal Chem 82: 739-742.

40. Seguchi M, Kanenaga K (1997) Study of three-dimensional structure of wheat starch granules stained with Remazolbrilliant blue dye and extracted with aqueous sodium dodecyl sulfate and mercaptoethanol solution. Cereal Chem 74: 548-552.

41. Lowy GDA, Sargeant JG, Schofield JD (1981) Wheat starch granule protein: the isolation and characterisation of a salt-extractable protein from starch granules. $J \mathrm{Sci}$ Food Agric 32: 371-377.

42. Greenwell P, Evers AD, Gough BM, Russell PI (1985) Amyloglucosidase-catalysed erosion of native, surface-modified and chlorine-treated wheat starch granules. The influence of surface protein. J Cereal Sci 3: 279-293.

43. Greenwell P, Schofield JD (1986) Astarch granule protein associated with endosperm softness in wheat. Cereal Chem 63: 379-380.

44. Skerritt JH, Frend AJ, Robson LG, Greenwell P (1990) Immunological homologies between wheat gluten and starch granule proteins. J Cereal Sci 12: 123-136.

45. Sulaiman BD, Morrison WR (1990) Proteins associated with the surface of wheat starch granules purified by centrifuging through caesium chloride. J Cereal Sci 12: 53-61.

46. Skerritt JH, Hill AS (1992) How "free" is "gluten free"? Relationship between Kjeldahl nitrogen values and gluten protein content for wheat starches. Cereal Chem 69: 110112.

47. Malouf RB, Lin WDA, Hoseney RC (1992) Wheat hardness. II. Effects of starch granule protein on endosperm tensile strength. Cereal Chem 69: 169-173.

48. Baldwin PM, Melia CD, Davies MC (1997) The surface chemistry of starch granules studied by time-of-flight secondary ion mass spectrometry. J Cereal Sci 26: 329-346.

49. Han XZ, Hamaker BR (2002) Association of starch granule proteins with starch ghosts and remnants revealed by confocal laser scanning microscopy. Cereal Chem 79: 892896.

50. Russo JV, Doe CA (1970) Heat treatment of flour as an alternative to chlorination. $J$ Food Technol 5: 363-374.

51. Doe CAF, Russo JVB (1968) Flour treatment process. British Patent 1, 110, 711.

52. Hanamoto MM, Mean BM (1978) Alternatives to chlorination for cake flours. Cereal Foods World 23: 459.

53. Russo JVB, Doe CAF (1970) Flour treatment process. U.S. Patent 3, 490, 917.

54. Clements RL, Donelson JR (1982) Role of free flour lipids in batter expansion in layer cakes. II. Effects of heating. Cereal Chem 59: 125-128.

55. Clements RL, Donelson JR (1982) Role of free flour lipids in batter expansion in layer cakes. I. Effects of "aging". Cereal Chem 59: 121-124.

56. Seguchi M (1990) Effect of heat-treatment of wheat flour on pancake springiness. $J$ Food Sci 55: 784-785.
57. Ozawa M, Seguchi M (2006) Relationship between pancake springiness and interaction of wheat flour components caused by dry heating. Food Sci Technol Res 12: 167-172.

58. Seguchi M, Hayashi M, Kanenaga K, Ishihara C, Noguchi S (1998) Springiness of pancake and its relation to binding of prime starch to tailings in stored wheat flour. Cereal Chem 75: 37-42.

59. Seguchi M (1984) Oil-binding ability oh heat-treated wheat starch. Cereal Chem 61: 248-250.

60. Seguchi M (1986) Lipid binding to the surface of wheat starch granules. Cereal Chem 63: 311-315.

61. Seguchi M, Yamada Y (1988) Hydrophobic character of heat-treated wheat starch Cereal Chem 65: 375-376.

62. Seguchi M (1991) Effects of chlorination and heat-treatment of wheat flour on starchy foods. Denpun Kagaku 38: 271-279.

63. Seguchi M (2001) Oil binding ability of chlorinated and heated wheat starch granules and their use in breadmaking and pancake baking. Starch 53: 408-413.

64. Seguchi M, Kusunose C (2001) Lipophilization of curdlan granules by heat-treatment or chlorination. Food Hydrocoll 15: 177-183.

65. Ozawa M, Seguchi M (2008) Effect of dry-heated prime starch and tailings fractions in wheat flour on pancake springiness. Cereal Chem 85: 626-628.

66. Ozawa M, Kato Y, Seguchi M (2009) Investigation of dry-heated hard and soft wheat flour. Starch 61: 398-406.

67. Nakamura C, Seguchi M (2007) Studies of improving effects of stored wheat flour on pancake texture. Food Sci Technol Res 13: 221-226.

68. Seguchi M, Takemoto M, Mizutani U, Ozawa M, Nakamura C, et al. (2004) Effects of secondary structures of heated egg white protein on binding between prime starch and tailing fractions in fresh wheat flour. Cereal Chem 81: 633-636.

69. Susi H, Byler DM (1983) Protein structure by Fourier transform infrared spectroscopy: second derivative spectra. Biochem Biophys Res Commun 115: 391-397.

70. Susi H, Byler DM (1986) Resolution-enhanced Fourier transform infrared spectroscopy of enzymes. Methods Enzymol 130: 290-311. [Crossref]

71. Deshpande SS, Damodaran S (1989) Effect of heat treatment on chemically modified proteins of legume seeds. Biochim Biophys Acta 998: 179-188.

72. Matsudomi N, Kato A, Kobayashi K (1982) Conformation and surface properties of deamidated gluten. Agric Biol Chem 46: 1583-1586.

73. Seguchi M, Yamada Y (1988) Hydrophobic character of heat-treated wheat starch Cereal Chem 65: 375-376.

74. Nakamura C, Koshikawa Y, Seguchi M (2007) Effect of flour changes due to storage on kasutera cake volume. Food Sci Technol Res 13: 351-355.

75. Nakamura C, Koshikawa Y, Seguchi M (2008) Increased volume of kasutera cake (Japanese sponge cake) by dry heating of wheat flour. Food Sci Technol Res 14: 431436

76. Tabara A, Oneda H, Murayama R, Matsui Y, Hirano A, et al. (2014) Determination of hydrophobicity of dry-heated wheat starch granules using sucrose fatty acid esters (SFAE). Biosci Biotechnol Biochem 78: 1572-1576. [Crossref]

77. Tabara A, Nakagawa M, Ushijima Y, Matsumura K, Seguchi M (2015) Effects of heat treatment on oil-binding ability of rice flour. Biosci Biotechnol Biochem 79: 1629-1634. [Crossref]

78. Nakagawa M, Tabara A, Ushijima Y, Matsunaga K, Seguchi M (2016) Hydrophobicity of stored $\left(15,35^{\circ} \mathrm{C}\right)$, or dry-heated $\left(120^{\circ} \mathrm{C}\right)$ rice flour and deteriorated breadmaking properties baked with these treated rices flour/fresh gluten flour. Biosci Biotechnol Biochem 80: 983-990. [Crossref]

79. Morton WM (1969) Effects of freezing and hardening on the sulfhydryl groups of protein fractions from cabbage leaves. Plant Physiol 44: 168-172. [Crossref]

80. Ushijima Y, Nakagawa M, Tabara A, Matsunaga K, Seguchi M (2017) Improvement of the bread-making properties of stored or dry-heated rice flour with sucrose fatty acid ester. Food Sci Technol Res 23: 291-295.

Copyright: $(2020$ Seguchi M. This is an open-access article distributed under the terms of the Creative Commons Attribution License, which permits unrestricted use, distribution, and reproduction in any medium, provided the original author and source are credited. 